\title{
CANCER RISK ASSESSMENT AND SOURCE IDENTIFICATION OF HEAVY METALS IN A LOW TRAFFIC URBAN REGION
}

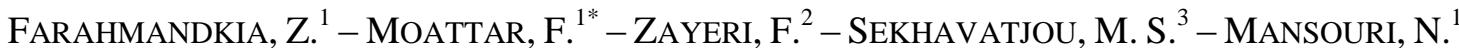 \\ ${ }^{I}$ Department of Environmental Engineering, Faculty of Environment and Energy, Science and \\ Research Branch, Islamic Azad University, Tehran, Iran \\ ${ }^{2}$ Department of Biostatistics, Faculty of Paramedical Sciences, Shahidbeheshti University of \\ Medical Sciences, Tehran, Iran \\ ${ }^{3}$ Department of Environmental Engineering, Islamic Azad University, Ahvaz Branch, Ahvaz, \\ Khouzestan, Iran \\ ${ }^{*}$ Corresponding author \\ e-mail:f-moatar@srbiau.ac.ir \\ (Received $31^{\text {st }}$ Oct 2016; accepted $30^{\text {th }}$ Dec 2016)
}

\begin{abstract}
Heavy metals are amongst the most hazardous pollutants which threaten human health due to their accumulative property and lack of decomposition in the body. In order to measure these metals, sampling was implemented on particles smaller than ten microns $\left(\mathrm{PM}_{10}\right)$ from a station in low-traffic region once a week for two years. Fifteen heavy metals were measured while cancer risk assessment of metals including arsenic, cadmium, chromium, nickel and lead was implemented in three maximum, minimum and average concentration ranges. Results for children and adults living in the region indicated that cancer risk indexes in most of the cases were between $10^{-6}$ and $10^{-4}$. According to EPA recommendations, in this situation, planning should be conducted to reduce cancer risk. In this study, source identification and apportionment of pollutants were implemented by all measured heavy metals using PMF5 model. It was found that the contribution of lead and zinc industries to emission of carcinogen metals was $42.3 \%$ for their waste dump soil, and suspended open soil, industrial activities, traffic and, fuel and combustion were other sources. It was also found that more than $80 \%$ of the cadmium is released from suspended open soil.
\end{abstract}

Keywords: air pollution, Zanjan, Iran, PM ${ }_{10}$, released cadmium, suspended soil, emissions control, Environmental Protection Agency

\section{Introduction}

With the advancement of technology and industrialization of cities, air pollution increased and subsequently higher rate of disease and cancer make the residents suffer. Absorption and accumulation and lack of decomposition of heavy metals in the body are the main reason that they are introduced as the main urban air pollutants (AlKhashman, 2007; Yongming et al., 2006). Usually in areas prone to heavy metal pollution, health risk assessment is implemented without identification of their sources (Tariq et al., 2006; W.H.O, 2000; W.H.O, 2010). In order to improvement in risk status the sources which cause the emission of health risk pollutants should be identified and the share of identified sources should be determined.

The present study was conducted in Zanjan, North West of Iran. Iran is the fourth largest producer of lead and zinc in Asia after China, Kazakhstan and India and Zanjan is the center of lead and zinc production of Iran. Zanjan possesses more than a hundred factories around the city associated with lead and zinc industry. Anguran as Iran's largest zinc and lead mine is also located in Zanjan province. The studies have proved that heavy metals are present in concentrations larger than standard level in water 
(Asrari, 2014), surface water (Parizanganeh et al., 2010), air (Farahmandkia et al., 2011) soil (Poorjafari et al., 2015; Sadovska, 2012) and plants (Khanna et al., 2015). But health risk assessment and source routing of air pollutants has not been conducted in this area. In this study, after measurement of heavy metals in air particles smaller than and equal to ten microns in low-traffic residential area, cancer risk was assessed for both children and adults residents. Then regional pollution sources and their contributions was determined using $\mathrm{PMF}_{5}$ model.

\section{Materials and Methods}

\section{Study Area}

Zanjan in North West of Iran is located at $36^{\circ} 41^{\prime} \mathrm{N}, 48^{\circ} 27^{\prime} \mathrm{E}$ with average height of 1620 meters. This city has an area of $81 \mathrm{~km}^{2}$ and a population of 480000 people in 2015. The annual precipitation in this area is about $295 \mathrm{~mm}$ and annual average air temperature is $10^{\circ} \mathrm{C}$. There is a discharge site of waste and tailing soil on the south side of the city near the zinc industrial complex with almost one $\mathrm{km}^{2}$ area. More than three million tons of waste soil is daily discharged in this site without any environmental concerns. Moreover there is a site with almost the same area on the east side of town within $16 \mathrm{~km}$ distance near to Zanjan lead and zinc factory allocated to the discharge of waste soils. Location of industrial complexes around the city is shown in Figure 1.

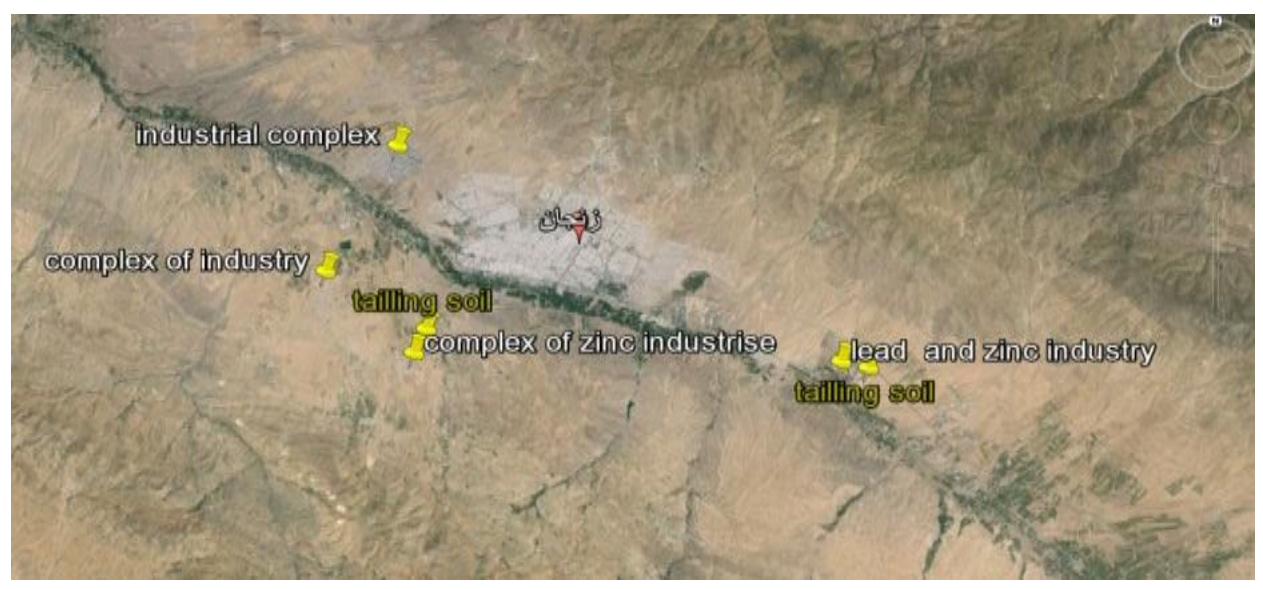

Figure 1. Zanjan map and surrounding sources of emission

\section{Methodology}

Sampling station was selected in eastern and residential area of the city far from city traffic. Sampling was conducted randomly once a week with high-volume sampling device (TCR-Tecora) to collect air $\mathrm{PM}_{10}$ sample. The quartz-fiber filter was used for sampling. Sampling was performed for 24-hour at a flow rate of $16.7 \mathrm{~L} / \mathrm{m}$. 96 samples were collected from June 2013 to 2015. The samples were digested by microwave digester (Sineo, MDS-10 model) based on USEPA-IO-3.1microwave method. Then ICP-OES device was used for measurement of metals including arsenic, aluminum, cadmium, calcium, chromium, copper, iron, manganese, nickel, lead, antimony, vanadium, titanium, zinc, and mercury. Parameters required for measuring metals using ICP device are shown in Tables 1 and 2. 
Table 1. Parameters for ICP-OES operation

\begin{tabular}{ll}
\hline Parameter & Values \\
\hline RF generator $(\mathbf{W})$ & 1400 \\
\hline Plasma torch & auxiliary \\
\hline Nebulizer gas & Argon \\
\hline Plasma gas flow rate $(\mathbf{l} / \mathbf{m i n})$ & 14.5 \\
\hline Nebulizer gas flow rate $(\mathbf{l} / \mathbf{m i n})$ & 0.85 \\
\hline Auxiliary gas flow rate $(\mathbf{l} / \mathbf{m i n})$ & 0.9 \\
\hline Sample uptake time $(\mathbf{S})$ & 240 total \\
\hline Rinse time of $(\mathbf{S})$ & 60 \\
\hline Measurement replicate & 3 \\
\hline Initial stabilization time $(\mathbf{S})$ & Preflush:60 \\
\hline Element $(\lambda / \mathbf{n m})$ & As below \\
\hline Frequency of RF generator $(\mathbf{M H z})$ & resonance frequency: $27.12 \mathrm{MHz}$ \\
\hline Type of detector Solid state & CCD \\
\hline Type of spray chamber Cyclonic & Modified Lichte \\
\hline
\end{tabular}

Table 2. Concentration of heavy metals in PM 10 particles in $\mu \mathrm{g} / \mathrm{m}^{3}$

\begin{tabular}{llll}
\hline Species & MIN & AVERAGE & MAX \\
\hline $\mathbf{W}$ & 25.000000 & 40.119388 & 67.900000 \\
\hline $\mathbf{A L}$ & 0.092050 & 0.207255 & 0.408026 \\
\hline $\mathbf{A s}$ & 0.000170 & 0.000295 & 0.000450 \\
\hline $\mathbf{C a}$ & 0.405500 & 1.084568 & 2.323402 \\
\hline $\mathbf{C d}$ & 0.000542 & 0.003620 & 0.009794 \\
\hline $\mathbf{C r}$ & 0.000042 & 0.000392 & 0.001126 \\
\hline $\mathbf{C u}$ & 0.007667 & 0.016249 & 0.038394 \\
\hline $\mathbf{F e}$ & 0.387500 & 0.768390 & 2.089105 \\
\hline $\mathbf{M n}$ & 0.012583 & 0.023915 & 0.041816 \\
\hline $\mathbf{N i}$ & 0.001125 & 0.002651 & 0.005720 \\
\hline $\mathbf{P b}$ & 0.014983 & 0.038664 & 0.080900 \\
\hline $\mathbf{S b}$ & 0.000208 & 0.001601 & 0.003440 \\
\hline $\mathbf{T i}$ & 0.000500 & 0.002683 & 0.005047 \\
\hline $\mathbf{V}$ & 0.000090 & 0.000116 & 0.000154 \\
\hline $\mathbf{Z n}$ & 0.078417 & 0.180970 & 0.340886 \\
\hline $\mathbf{H g}$ & 0.000165 & 0.001922 & 0.009464
\end{tabular}

\section{Health Risk Assessment}

Arsenic, cadmium, chromium, nickel and lead have been selected as cancer risk metal (Park et al., 2008). Because chromium 6 is carcinogenic, chromium 3 is safe and chromium 6 is in the air with a ratio of 1 to 6 , chromium value was divided by 7 in risk calculations (Hieu and Lee, 2010; EPA, 2001; EPA, 1989). Cancer risk assessment 
method was calculated by the method recommended by the EPA using equations (1) and (2) for minimum, average and maximum concentration. The parameters used in this study are shown in Table (3). In health risk assessment with carcinogens, there is a linear relation between higher of concentration emissions and increment of cancer risk. Slope made in this relation is the slope factor (SF) and its unit is expressed based on milligrams of chemical per kilogram of body weight per day. The results of above calculation could be seen in Tables 4 and 5. (EPA, 2009; Paatero, 1997; Mazzei et al., 2007).

$$
\begin{gathered}
\mathrm{AD}_{\mathrm{inh}}=\left(\mathrm{C} * \mathrm{IR}_{\mathrm{inh}} * \mathrm{ET}^{*} \mathrm{EF} * \mathrm{ED}\right) /(\mathrm{BW} * \mathrm{AT}) \\
\mathrm{CANCER} \mathrm{RISK}=\mathrm{AD}_{\mathrm{inh}} * \mathrm{SF}
\end{gathered}
$$

Table 3. Parameters applied in exposure assessment model

\begin{tabular}{cllll}
\hline parameter & definition & unit & Children & adults \\
\hline $\mathbf{A D}_{\text {inh }}$ & absorbed dose of inhalation & $\mathrm{mg} /(\mathrm{kg} \cdot$ day $)$ & & \\
\hline C & Concentration of metals & $\mathrm{mg} / \mathrm{m}^{3}$ & & \\
\hline SFinh & slope factor & $(\mathrm{kg} \bullet$ day $) / \mathrm{mg})$ & & \\
\hline ET & Exposure Time & $\mathrm{h} / \mathrm{d}$ & 24 & 24 \\
\hline EF & Exposure Frequency & $\mathrm{d} / \mathrm{year}$ & 350 & 350 \\
\hline ED & Exposure Duration & year & 8 & 35 \\
\hline AT & Average Time & $\mathrm{d}$ & $70 * 365$ & $70 * 365$ \\
\hline BW & Body Weight & $\mathrm{kg}$ & 20 & 65 \\
\hline IRinh & Inhalation Rate & $\mathrm{m} 3 / \mathrm{h}$ & 0.4 & 0.6 \\
\hline
\end{tabular}

Table 4. Results for children living in the region

\begin{tabular}{llllll}
\hline METALS & & ${\text { con. }\left(\mathbf{m g} / \mathbf{m}^{\mathbf{3}}\right)}$ & AD $_{\text {inh }}(\mathbf{m g r} / \mathbf{K g . d})$ & SF(Kg.d/mgr $)$ & CANCER RISK \\
\hline As & Max & $4.50 \mathrm{E}-07$ & $2.36712 \mathrm{E}-08$ & 15.1 & $3.57436 \mathrm{E}-07$ \\
\hline & Min & $1.70 \mathrm{E}-07$ & $8.94247 \mathrm{E}-09$ & 15.1 & $1.35031 \mathrm{E}-07$ \\
\hline Cd & MEAN & $2.95 \mathrm{E}-07$ & $1.55178 \mathrm{E}-08$ & 15.1 & $2.34319 \mathrm{E}-07$ \\
\hline & Max & $9.79 \mathrm{E}-06$ & $5.15191 \mathrm{E}-07$ & 6.1 & $3.14267 \mathrm{E}-06$ \\
\hline & Min & $5.42 \mathrm{E}-07$ & $2.85107 \mathrm{E}-08$ & 6.1 & $1.73915 \mathrm{E}-07$ \\
\hline $\mathbf{C r}$ & MEAN & $3.62 \mathrm{E}-06$ & $1.90422 \mathrm{E}-07$ & 6.1 & $1.16157 \mathrm{E}-06$ \\
\hline & Max & $1.61 \mathrm{E}-07$ & $8.46152 \mathrm{E}-09$ & 41 & $3.46922 \mathrm{E}-07$ \\
\hline & Min & $6.00 \mathrm{E}-09$ & $3.15616 \mathrm{E}-10$ & 41 & $1.29403 \mathrm{E}-08$ \\
\hline $\mathbf{N i}$ & MEAN & $5.60 \mathrm{E}-08$ & $2.94575 \mathrm{E}-09$ & 41 & $1.20776 \mathrm{E}-07$ \\
\hline & Max & $5.72 \mathrm{E}-06$ & $3.00888 \mathrm{E}-07$ & 0.84 & $2.52746 \mathrm{E}-07$ \\
\hline & Min & $1.13 \mathrm{E}-06$ & $5.91781 \mathrm{E}-08$ & 0.84 & $4.97096 \mathrm{E}-08$ \\
\hline Pb & MEAN & $2.65 \mathrm{E}-06$ & $1.3945 \mathrm{E}-07$ & 0.84 & $1.17138 \mathrm{E}-07$ \\
\hline & Max & $8.09 \mathrm{E}-05$ & $4.25556 \mathrm{E}-06$ & 0.042 & $1.78734 \mathrm{E}-07$ \\
\hline & Min & $1.50 \mathrm{E}-05$ & $7.88147 \mathrm{E}-07$ & 0.042 & $3.31022 \mathrm{E}-08$ \\
\hline
\end{tabular}


Table 5. Results for adults living in the region

\begin{tabular}{|c|c|c|c|c|c|}
\hline METALS & & $\operatorname{con} .\left(\mathrm{mg} / \mathrm{m}^{3}\right)$ & $\mathrm{AD}_{\mathrm{inh}}(\mathrm{mgr} / \mathrm{Kg.d})$ & SF(Kg.d/mgr) & CANCER RISK \\
\hline \multirow[t]{3}{*}{ As } & Max & $4.50 \mathrm{E}-07$ & 4.77977E-08 & 15.1 & $7.21745 \mathrm{E}-07$ \\
\hline & Min & $1.70 \mathrm{E}-07$ & 1.80569E-08 & 15.1 & $2.72659 \mathrm{E}-07$ \\
\hline & MEAN & $2.95 \mathrm{E}-07$ & $3.1334 \mathrm{E}-08$ & 15.1 & 4.73144E-07 \\
\hline \multirow[t]{3}{*}{ Cd } & Max & 9.79E-06 & 1.04029E-06 & 6.1 & $6.34577 \mathrm{E}-06$ \\
\hline & Min & $5.42 \mathrm{E}-07$ & $5.75697 \mathrm{E}-08$ & 6.1 & $3.51175 \mathrm{E}-07$ \\
\hline & MEAN & $3.62 \mathrm{E}-06$ & $3.84506 \mathrm{E}-07$ & 6.1 & 2.34549E-06 \\
\hline \multirow[t]{3}{*}{$\mathrm{Cr}$} & Max & $1.61 \mathrm{E}-07$ & $1.70858 \mathrm{E}-08$ & 41 & $7.00516 \mathrm{E}-07$ \\
\hline & Min & $6.00 \mathrm{E}-09$ & $6.37302 \mathrm{E}-10$ & 41 & $2.61294 \mathrm{E}-08$ \\
\hline & MEAN & 5.60E-08 & 5.94816E-09 & 41 & 2.43874E-07 \\
\hline \multirow[t]{3}{*}{$\mathbf{N i}$} & Max & 5.72E-06 & $6.07562 \mathrm{E}-07$ & 0.84 & 5.10352E-07 \\
\hline & Min & $1.13 \mathrm{E}-06$ & 1.19494E-07 & 0.84 & $1.00375 \mathrm{E}-07$ \\
\hline & MEAN & $2.65 \mathrm{E}-06$ & $2.81581 \mathrm{E}-07$ & 0.84 & $2.36528 \mathrm{E}-07$ \\
\hline \multirow[t]{3}{*}{$\mathbf{P b}$} & $\operatorname{Max}$ & $8.09 \mathrm{E}-05$ & 8.59296E-06 & 0.042 & 3.60904E-07 \\
\hline & Min & $1.50 \mathrm{E}-05$ & $1.59145 \mathrm{E}-06$ & 0.042 & $6.68409 \mathrm{E}-08$ \\
\hline & MEAN & $3.87 \mathrm{E}-05$ & $4.10678 \mathrm{E}-06$ & 0.042 & $1.72485 \mathrm{E}-07$ \\
\hline
\end{tabular}

\section{Identification and Apportionment of Emission Sources}

Positive matrix factorization (EPA-PMF5), is a multivariate receptor based model.It was used for source apportionment and characterization of the collected PM (Norris and Duvall, 2014). In PMF model $p$ factors (sources) which can be involved in a receptor site is stated with the following equation (3 and 4):

$$
\mathrm{X}_{\mathrm{ij}}=\sum_{k=1}^{p}\left(g_{i k} \times f_{k j}\right)+E_{i j}
$$

Where,

$X_{i j}$ Concentration of species $\mathrm{J}$ in ith sample

$g_{i k}$ Contribution of kth factor to the ith sample

$f_{k j}$ Fraction of kth factor that is species $\mathrm{j}$ or chemical composition profile of factor $\mathrm{K}$

$E_{i j}$ Residual for the jth species on the ith sample

The contributions of factor $\left(g_{i k}\right)$ and source profiles $\left(f_{k j}\right)$ are estimated by the PMF model by minimizing the objective function:

$$
Q=\sum_{i=1}^{n} \sum_{j=1}^{m}\left(\frac{x_{i j-} \Sigma_{r=1}^{p} g_{i k} \times f_{k j}}{u_{i j}}\right)
$$

$u_{i j}:$ Uncertainty of species Jth the sample (4).

Q: a critical parameter for PMF model. 
Minimizing the sum of squares of standardized residuals or $\mathrm{Q}$ is the main aim of EPA PMF. In PMF, the weight of missing and below-detection-limit data would decrease with appropriate uncertaint (Norris and Duvall, 2014). PMF has the ability to underweight the missing data and values below detection limit, and can reduce the influence of extreme values using robust mod (Reff et al., 2007). The uncertainties of the species were determined according to the EPA-PMF5 manual (Norris and Duvall, 2014). The data with concentrations below MDL, substituted by $1 / 2 \mathrm{MDL}$ and 5/6 MDL was used as the corresponding uncertainty value (Brown et al., 2015). The uncertainty of the data with concentration greater than MDL, was determined using the equation 5 (Mansha et al., 2012).

$$
\mathrm{UNC}=\sqrt{(\text { Error fraction } \times \text { concentration })^{2}+(M D L / 2)^{2}}
$$

As described by Nooris et al. (2014) and detailed in Paatero et al. (2014), EPA PMF has 2 main error estimation methods: displacement (DISP), Bootstrapping (BS) (Mansha et al., 2012; Begum et al., 2004). DISP includes the effects of rotational ambiguity and does not affect random errors in the data. BS includes the effects of random errors and partially-rotational ambiguity.

\section{Results and Discussion}

\section{Cancer Risk Assessment}

Cancer risk assessment calculation results in a low-traffic area for children and adults are shown in tables 4 and 5. According to the EPA recommendation (Wang et al., 2010), when risk index ranges between $10^{-6}$ to $10^{-4}$ index is accepted however pollution control would be necessary. The risk calculated for five heavy metals in present study was implemented in three concentration ranges from minimum, average and maximum for both children and adults groups. It was observed that the highest risk of cadmium in children and adults are related to two ranges of maximum and average concentrations which were respectively $3.14 * 10^{-6}$ and $1.16^{*} 10^{-6}$ for children and $6.3 * 10^{-6}$ and $2.34 * 10^{-}$ ${ }^{6}$. To determine the emission source of metal, the identification and apportion sources of pollutants are necessary for further environmental health management and controlling measures of emissions.

\section{Source Identification of Pollutants Using PMF5 Model}

With 96 samples including 15 measured heavy metals, PMF5 was implemented for status with 4, 5 and 6 emission factors.

\section{Four-Factor Run}

In this run, factor 1 is associated with industrial activities with $23.5 \%$ share which includes nickel and chromium indices. There are electroplating, knife and copper workshops for making copper containers both decorative and utilizable which could be source of air particles. Factor 2 with the highest share of emission with index species of lead and zinc contributes to $42.3 \%$ of pollution. This factor which is related to lead and zinc industries and waste depot in the region contributes to $42.3 \%$ of pollution. This factor is related to lead and zinc industries and tailing soil depot in the region. Waste 
and tailing soils of lead and zinc industry are stacked in two sites of Zanjan which are shown in figure (1). One of these sites is located in the vicinity of specialized zinc complex in the southeast of Zanjan. The filter cake and waste soil of entire zinc factories in the specialized complex are discharged in this site. The soils are daily discharged and piled up in this site without any environmental considerations. Now more than 3 million tons of waste soil has been piled up in the area. Similarly, another area is located within sixteen kilometers East of Zanjan, in vicinity of lead and zinc plant in which the waste and soils of aforesaid factory is discharged. Factor 3 is associated with suspended open soil with $26.4 \%$ share including indicator species of cadmium, aluminum, calcium and iron. Cadmium is one of the specific species with the highest percentage share. In the other words, with the increase in species associated with soil, this element has been increased. The main reason is indiscriminate use of chemical fertilizers in the surrounding areas on agricultural lands which has significantly increased. The study by Zanjan Agricultural Research center indicated that concentration of cadmium in agricultural soils of lands surrounding Zanjan is more than the standard limit. Factor 4 with the lowest share in the region is associated with the fuel, combustion and traffic which are related to species of mercury, vanadium and arsenic with share of $7.8 \%$. Since different studies use wide variety of organic or mineral or a combination of both, depending on researcher's knowledge of regional pollutions, these species are not defined as a definite indicators, however in abundant studies using mineral species, indices of area studied in this research are consistent with the indicators in following studies (Cohen et al., 2010).

\section{Five-Factor Solution}

In five factor solution, most of the contaminations were related to Factor 1 identified with indicator species of lead and zinc which share of $28.2 \%$. This factor was related to lead and zinc industries and waste depot in the region. This factor is coincided with factor 2 in four-factor solution with share of $42.3 \%$. The second factor with greater share is factor 3 with $27.5 \%$ share including calcium, aluminum, iron, nickel and, manganese species. It seems that this factor was isolated from species of lead and zinc industries, waste depot and factors related to the industry and electroplating activities. The third factor with share of $26.2 \%$ is related to species of cadmium, aluminum, calcium and iron associated with suspended open soil and is consistent with factor 3 in four-factor solution. The fourth factor with share of $12 \%$ is related to chromium, nickel, titanium and vanadium applied in industry and electroplating activities which is consistent with factor 1 in four-factor solution. The fifth factor with share of $1.6 \%$ is related to mercury, vanadium and arsenic species associated with traffic and fuel combustion and is consistent with factor 4 in four-factor solution.

\section{Six-Factor Solution}

Factor 1 with a share of $6.2 \%$ is related to indicator species of mercury, vanadium and arsenic associated with traffic and fuel combustion. Factor 2 with nickel, aluminum, titanium, iron and, antimony species had a share of $28.5 \%$. Factor 3 with calcium, cadmium, aluminum, iron and copper species had a share of $10.6 \%$. Factor 4 with cadmium, calcium, titanium and, nickel species had a share of $17.5 \%$. Factor 5 with lead and zinc species with a share of $7 / 27$ is related to lead and zinc industries and waste 
depot in the area. Factor 6 with chromium, nickel and titanium species with a share of $9.6 \%$ is related to industry and electroplating activities in the area.

As an overall result of these solutions it could be said that with regard to Q / $\mathrm{Q}_{\text {exp }}$ values which was 0.643 in four-factor solution, 0.539 in five-factor solution and 0.481 in six-factor solution, the four-factor solution brings about better results while fuel and traffic factors, suspended open soil, lead and zinc, waste and industrial activities are the most important factors identified in this area. Furthermore, we could compare the solutions based on the error estimation parameters. The model used bootstrap instrument to estimate the error of random data and displacement instrument to estimate rotation error.

The results of the base run were tested by error estimating tools of bootstrap and displacement moods. These tools showed that four-factor solution is the best answer with minimum error.

\section{Main Source of Emission \& Percent of Affective Heavy Metals In Cancer Risk}

In four-factor solution as the best solution, share of the intended metal in cancer risk could be seen in each of the pollutant factors in Figure 2. Cadmium with the share of $80.6 \%$ exhibited cancer risk in maximum and average concentration for children and adults. It was associated with re-suspended open soil with $26.4 \%$ share of the pollution in the city. $12.9 \%$ of $\mathrm{Cd}$ is also emitted from factor 1 (industrial activities) and with share of $23.5 \%$ in the city atmosphere.

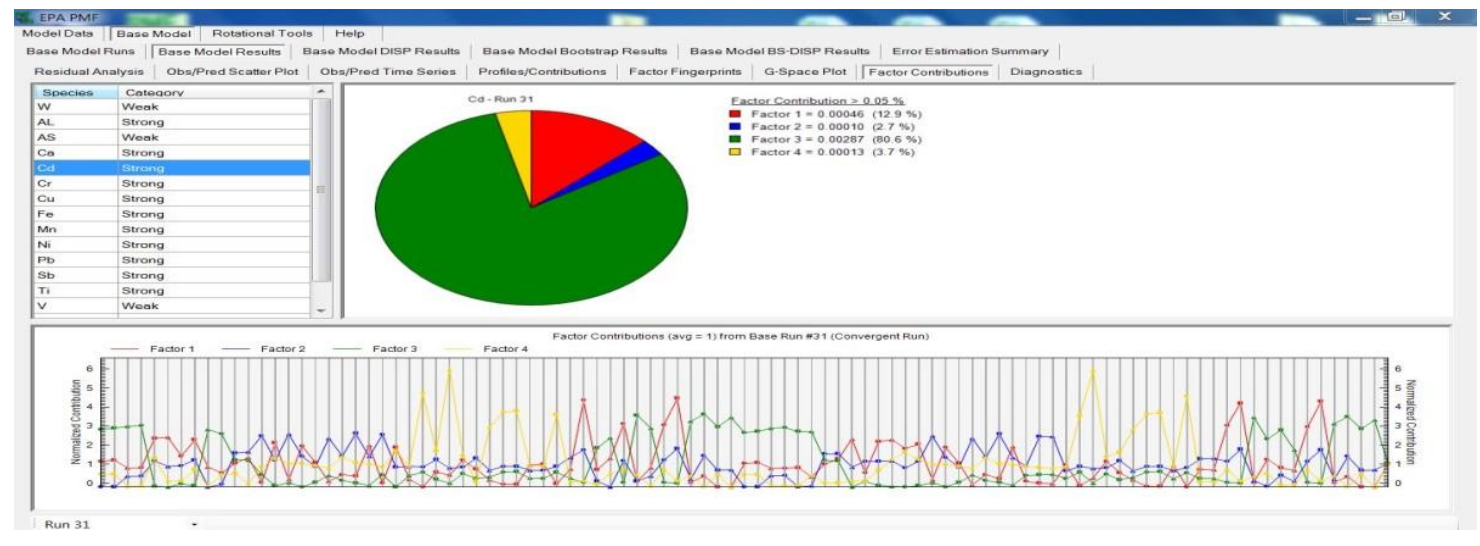

Figure 2. Share of cadmium in emission source

\section{Conclusion}

The cancer risk assessment of metals including arsenic, cadmium, chromium, nickel and lead concentrations in three maximum, minimum and average ranges conducted on two groups of children and adults living in the area showed that cancer risk for children was in maximum concentration of cadmium $3.14 * 10^{-6}$ and average concentration $1.16^{*} 10^{-6}$. The cancer risk for adults was in maximum concentration of cadmium $6.03 * 10^{-6}$ and average concentration of cadmium $2.3 * 10^{-6}$. The results showed that four dominant pollutants in cities include lead and zinc industry with a $42.3 \%$ share of emission, suspended open soil with $26.4 \%$ share of emission, industrial activities with $23.5 \%$ share of emission and fuel and combustion with $23.5 \%$ share of emission. 
It was also found that more than $80 \%$ of released cadmium is originated from the resuspended soil. The amount of cadmium in soil is high due to indiscriminate use of chemical fertilizers and industrial activities. To reduce the risk of cancer, management plans and measures to control emissions, especially cadmium, and extension of industrial activities in the territory of the metropolitan area should be prioritized. The remarkable point in present study is that although suspended open soil has higher cancer risk however it is not the dominant pollutant of the area. The model showed that health risk metals are not necessarily present in dominant source of air particles.

\section{REFERENCES}

[1] Al-Khashman, O.A. (2007): Determination of metal accumulation in deposited street dusts in Amman, Jordan. - Environmental Geochemistry and Health 29(1): 1-10.

[2] Asrari, E. (2014): Heavy Metal Contamination of Water and Soil Analysis, Assessment, and Remediation Strategies. - Apple Academic Press.

[3] Begum, B.A., et al. (2004): Investigation of sources of atmospheric aerosol at urban and semi-urban areas in Bangladesh. - Atmospheric Environment 38(19): 3025-3038.

[4] Brown, S.G., et al. (2015): Methods for estimating uncertainty in PMF solutions: examples with ambient air and water quality data and guidance on reporting PMF results. - Science of The Total Environment 518: 626-635.

[5] Cohen, D.D., et al. (2010): Characterisation and source apportionment of fine particulate sources at Hanoi from 2001 to 2008. - Atmospheric Environment 44(3): 320-328.

[6] EPA /540/1-89/002;USEPA (1989). Washington, D., USA, Risk Assessment Guidance for Superfund: Human Health Evaluation Manual (Part A); Volume 1.

[7] EPA-540-R-070-002-OSWER9285 (2009). Risk Assessment Guidance for Superfund: Human Health Evaluation Manual (Part F, Supplemental Guidance for Inhalation Risk Assessment); Washington, D.C. pp. 7-82.

[8] EPA 540-R-02002;USEPA (2001). Washington, D., USA, .Risk Assessment Guidance for Superfund: Process for conducting Probabilistic Risk Assessment (Part A); Volume 3.

[9] Farahmandkia, Z., Mehrasbi, M., and Sekhavatjou, M.(2011): Relationship Between Concentrations Of Heavy Metals In Wet Precipitation And Atmospheric $\mathrm{Pm}^{\wedge}$ Sub $10^{\wedge}$ Particles In Zanjan, Iran. - Iranian Journal of Environmental Health Science \& Engineering 8(1): 49.

[10] Hieu, N.T. Lee, B.K. (2010): Characteristics of particulate matter and metals in the ambient air from a residential area in the largest industrial city in Korea. - Atmospheric Research 98(2): 526-537.

[11] Khanna, I., Khare, M., Gargava, P.(2015): Health risks associated with heavy metals in fine particulate matter: a case study in Delhi city, India. - Journal of Geoscience and Environment Protection 3(02): 72.

[12] Mansha, M., et al. (2012): Characterization and source apportionment of ambient air particulate matter (PM2.5) in Karachi. - Sci Total Environ 425: 176-83.

[13] Mazzei, F., et al. (2007): A new methodological approach: the combined use of two-stage streaker samplers and optical particle counters for the characterization of airborne particulate matter. - Atmospheric Environment 41(26): 5525-5535.

[14] Norris, G., Duvall, R. (2014): EPA Positive Matrix Factorization (PMF) 5.0 Fundamentals and User Guide. U.S. Environmental Protection Agency EPA/600/R14/108, Editor. September 2014, National Exposure Research Laboratory Research Triangle Park,: Petaluma. 1-136.

[15] Paatero, P.(1997): Least squares formulation of robust non-negative factor analysis. Chemometrics and intelligent laboratory systems 37(1): 23-35. 
[16] Paatero, P., Eberly, S., Brown, S. G., Norris, G. A. (2014): Methods for estimating uncertainty in factor analytic solutions. - Atmos. Meas. Tech. 7: 781-797. doi:10.5194/amt-7-781-2014

[17] Parizanganeh, A., Hajisoltani, P., Zamani, A.(2010): Assessment of heavy metal pollution in surficial soils surrounding Zinc Industrial Complex in Zanjan-Iran. - Procedia Environmental Sciences 2: 162-166.

[18] Park, E.J., Kim, D.S., Park, K.(2008): Monitoring of ambient particles and heavy metals in a residential area of Seoul, Korea. - Environmental monitoring and assessment 137(13): 441-449.

[19] Poorjafari, N., et al. (2015): Assessment of residue melamine in dairy products exhibited in Zanjan market, Iran by high-performance liquid chromatography method. International Journal of Environmental Science and Technology,. 12(3): 1003-1010.

[20] Reff, A., Eberly, S.I., Bhave, P.V.( 2007): Receptor modeling of ambient particulate matter data using positive matrix factorization: review of existing methods. - Journal of the Air \& Waste Management Association 57(2): 146-154.

[21] Sadovska, V. (2012): Health Risk Assessment of Heavy Metals Adsorbed in Particulates.International Journal of Env. Chem. Ecol. Geol.Geoph. Eng. 6(8): 481-484.

[22] Tariq, S.R., et al. (2006): Multivariate analysis of trace metal levels in tannery effluents in relation to soil and water: A case study from Peshawar, Pakistan. - Journal of Environmental Management 79(1): 20-29.

[23] W.H.O (2000). Air quality guidelines for Europe.

[24] W.H.O (2010). Health and environment in Europe: Progress assessment.

[25] Wang, Y., et al. (2012): Source apportionment of airborne particulate matter using inorganic and organic species as tracers. - Atmospheric Environment 55: 525-532.

[26] Yongming, H., et al. (2006): Multivariate analysis of heavy metal contamination in urban dusts of Xi'an, Central China. - Science of The Total Environment 355(1): 176-186. 